REVIEW ARTICLE

\title{
Current Endocarditis Prophylaxis Guidelines and Incidence of Infection
}

\author{
Nikita Carvalho* \\ Interventional Cardiology, Columbia University Division of Cardiology, Mount Sinai Medical Center, USA
}

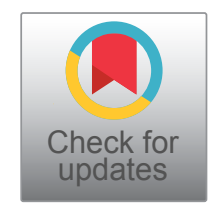

*Corresponding author: Nikita Carvalho, Interventional Cardiology, Columbia University Division of Cardiology, Mount Sinai Medical Center, 4300 Alton Road, Miami Beach, FL 33140, USA

\section{Introduction}

Infective endocarditis (IE) defined as an infection caused by bacteria that enter the bloodstream and settle in the endocardium, a heart valve or a blood vessel, has maintained a high prevalence, morbidity and mortality over the past few decades $[1,2]$. The most obvious changes over time have been in terms of factors that lead to IE. For e.g. A larger elderly population, decrease in Rheumatic heart disease (RHD) cases, Increased use of prosthetic heart valves, increased intravenous drug abuse, and increased rates of intravascular catheter-induced nosocomial infections [1]. Antibiotic prophylaxis has been recommended for invasive procedures such as dental extractions, genito-urinary procedures and gastrointestinal procedures, in those who have pre-disposing cardiac conditions $[3,4]$. These guidelines have interestingly undergone many modifications over time. In 2007, the American Heart Association (AHA) abolished routine prophylaxis before dental procedures except for those patients with the highest risk of adverse outcome resulting from IE which includes those with underlying cardiac conditions associated with the highest risk of adverse outcomes from endocarditis who undergo dental procedures that involve the manipulation of gingival tissue or the periapical region of teeth or perforation of the oral mucosa. Gastrointestinal and genito-urinary procedures required no prophylaxis as per the guidelines [5]. In 2008, the guidance from the National Institute for Health and Clinical Excellence (NICE) in the UK recommended that prophylaxis solely to prevent IE should not be given to people at risk of IE undergoing dental and non-dental procedures [6]. Following the revised NICE guidelines, usage of antibiotic prophylaxis went down with no perceivable increase in endocarditis infection rates [7]. In 2009, the European Society of Cardiology recommended antibiotic prophylaxis for dental procedures only in patients at very high risk (prosthetic heart valves, congenital heart disease and history of IE) [2]. This review aims at studying the epidemiology of IE, impact of the revised guidelines in various groups of people and procedures and determining the ideal approach to IE prophylaxis in different clinical scenarios.

\section{Trends in Infection Rates with Respect to Change in Guidelines}

Since the UK National Institute for Health and Care Excellence (NICE) modified its guidelines in 2008, the incidence of Infective endocarditis has risen significantly. A retrospective, secular trend study found that antibiotic prescriptions to prevent infective endocarditis had dropped from a mean of 10,900 per month between 1 January 2004 to 31 March 2008 (at the time of NICE guideline introduction) to a mean of 2,236 per month between 1 April 2008 to 31 March $2013(P<0.0001)$ [8]. During the last 6 months of the study, the mean number of prescriptions fell further to 1,307 per month. The team also identified that between 1 January 2000 and 31 March 2013, 19,804 patients were diagnosed primarily with acute or sub acute infective endocarditis. The trend in the incidence of infective endocarditis increased significantly after the introduction of the NICE guidelines expressed as 0.11 cases per 10 million individuals per month $(P<0.0001)$. By 31 March 2013, approximately 35 more cases of infective endocarditis had occurred per month than would have been expected if the NICE guideline had not been formulated. No signif-

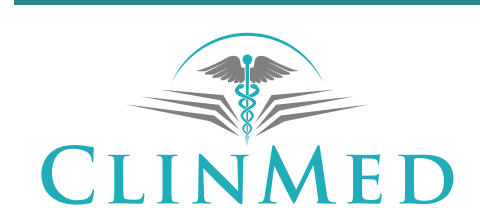

INTERNATIONAL LIBRARY

Citation: Carvalho N (2019) Current Endocarditis Prophylaxis Guidelines and Incidence of Infection. Int J Clin Cardiol 6:144. doi.org/10.23937/2378-2951/1410144

Accepted: May 28, 2019; Published: May 30, 2019

Copyright: (C) 2019 Carvalho N. This is an open-access article distributed under the terms of the Creative Commons Attribution License, which permits unrestricted use, distribution, and reproduction in any medium, provided the original author and source are credited. 
icant increase in infective endocarditis mortality was seen however, after 31 March 2008 ( $P=0.394)$. It was concluded that a temporal relation between prophylactic antibiotic use and incidence of infective endocarditis had been established although without proof of a causal link.

\section{Oral Procedures and Infective Endocarditis}

It is interesting to note, that there is no actual evidence which supports the link between antibiotic prophylaxis and prevention of infective endocarditis [9]. Moreover, it has been speculated that dental procedures might not even be a risk factor [10]. However, there have also been studies that have claimed that antibiotic prophylaxis may be helpful especially in highrisk patients $[11,12]$. Approximately $25 \%$ of all cases of endocarditis are caused by Viridans Group Streptococci (VGS) [13] while far fewer cases are caused by periodontal pathogens $[14,15]$. This is in accordance with the theory that eating and tooth brushing may be a greater risk factor for the development of IE than the transient bacteremia that follows an invasive dental procedure [16]. Thornhill, et al. designed a before and after study in order to quantify the change in prescription of antibiotic prophylaxis before invasive dental procedures for patients at risk of IE and any concurrent change in the incidence of IE, following the introduction of the 2008 NICE guidelines recommending the cessation of antibiotic prophylaxis [7]. They found a highly significant $78.6 \%$ reduction $(P<0.001)$ in prescribing of antibiotic prophylaxis, from a mean 10,277 (SD 1068) prescriptions per month to 2292 (SD 176). However, their study did not show any large increase in the incidence of cases or deaths from IE in the two years after the guideline.

\section{Urological Procedures and Infective Endocar- ditis}

Current guidelines do not recommend prophylaxis against IE for urinary tract procedures in the absence of active infection $[2,6]$. Urological procedures have, however, been linked with IE through various studies. The first study to show a statistical association between urological procedures and the development of IE was a retrospective study over a 10-year period on 384 patients which revealed a statistical association between the development of enterococcal IE and preceding urological procedures $(P<0.05)$. The study also found that increasing age and IV drug use was also associated with enterococcal IE. Interestingly, haemodialysis and the presence of an intracardiac device was found to be associated with the development of coagulase-negative staphylococcal IE [17]. It must be noted that although the present study shows a statistically significant association between urological procedures and enterococcal $\mathrm{IE}$, of 111 cases of enterococcal IE treated during the study, just 24 of them had a urological procedure in the year before presentation. There was no evidence of a causal relationship or evidence that antibiotics pro- phylaxis would improve the situation. Also, only cases caused by selected groups of pathogens were included.

\section{Body Art and Infective Endocarditis}

Several authors have emphasized [18] the need for patient awareness when it comes to undergoing piercings and tattooing on their skin especially in those with congenital heart disease. For example, Tse, et al. described the case of a man with aortic regurgitation who had several tattoos performed at a local parlour and subsequently developed endocarditis [19].

\section{Gastrointestinal Procedures and Infectious Endocarditis}

The Endoscopy Committee of the British Society of Gastroenterology recommends antibiotic prophylaxis for patients with severe neutropenia $(<0.5 \times 109 /$ l) and/or profound immunocompromise who undergo procedures at high risk of causing bacteremia [20].

\section{Discussion}

It would seem like introduction of guidelines to decrease prophylaxis before procedure does not seem to confer significant benefit and in some cases may even harm. More clinical trials are warranted and possibly guidelines may be changed in the future to allow for more permissive prophylaxis as is in place currently.

\section{References}

1. Moreillon P, Que YA (2004) Infective endocarditis. Lancet 363: 139-149.

2. Habib G, Hoen B, Tornos P, Thuny F, Prendergast B, et al. (2009) Guidelines on the prevention, diagnosis, and treatment of infective endocarditis (new version 2009): The Task Force on the Prevention, Diagnosis, and Treatment of Infective Endocarditis of the European Society of Cardiology (ESC). Endorsed by the European Society of Clinical Microbiology and Infectious Diseases (ESCMID) and the International Society of Chemotherapy (ISC) for Infection and Cancer. Eur Heart J 30: 2369-2413.

3. Durack DT (1998) Antibiotics for prevention of endocarditis during dentistry: Time to scale back? Ann Intern Med 129: 829-831.

4. Danchin N, Duval X, Leport C (2005) Prophylaxis of infective endocarditis: French recommendations 2002. Heart 91: 715-718.

5. Wilson W, Taubert KA, Gewitz M, Lockhart PB, Baddour LM, et al. (2008) Prevention of infective endocarditis: Guidelines from the American Heart Association A guideline from the American Heart Association Rheumatic Fever, Endocarditis and Kawasaki Disease Committee, Council on Cardiovascular Disease in the Young, and the Council on Clinical Cardiology, Council on Cardiovascular Surgery and Anesthesia, and the Quality of Care and Outcomes Research Interdisciplinary Working Group. J Am Dent Assoc 139: 3S-24S.

6. Centre for Clinical Practice at NICE (UK) (2008) Prophylaxis Against Infective Endocarditis: Antimicrobial Prophylaxis Against Infective Endocarditis in Adults and Children Undergoing Interventional Procedures. 
7. Thornhill MH, Dayer MJ, Forde JM, Corey GR, Chu VH, et al. (2011) Impact of the NICE guideline recommending cessation of antibiotic prophylaxis for prevention of infective endocarditis: Before and after study. BMJ 342: 2392.

8. Dayer MJ, Jones S, Prendergast B, Baddour LM, Lockhart PB, et al. (2014) Incidence of infective endocarditis in England, 2000-13: A secular trend, interrupted time-series analysis. Lancet 385: 1219-1228.

9. Lockhart PB, Loven B, Brennan MT, Fox PC (2007) The evidence base for the efficacy of antibiotic prophylaxis in dental practice. J Am Dent Assoc 138: 458-474.

10. Lacassin F, Hoen B, Leport C, Selton-Suty C, Delahaye $F$, et al. (1995) Procedures associated with infective endocarditis in adults. A case control study. Eur Heart J 16: 1968-1974.

11. Agha Z, Lofgren RP, VanRuiswyk JV (2005) Is antibiotic prophylaxis for bacterial endocarditis cost-effective? Med Decis Making 25: 308-320.

12. Ashrafian H, Bogle RG (2007) Antimicrobial prophylaxis for endocarditis: Emotion or science? Heart 93: 5-6.

13. Cabell CH, Abrutyn E (2002) Progress toward a global understanding of infective endocarditis: Early lessons from the International Collaboration on Endocarditis investigation. Infect Dis Clin North Am 16: 255-272.

14. Houston S, Taylor D, Rennie R (1997) Prosthetic valve endocarditis due to Veillonella dispar: Successful medical treatment following penicillin desensitization. Clin Infect Dis 24: 1013-1014.

15. Paturel L, Casalta JP, Habib G, Nezri M, Raoult D (2004) Actinobacillus actinomycetemcomitans endocarditis. Clin Microbiol Infect 10: 98-118.

16. Lockhart PB, Brennan MT, Sasser HC, Fox PC, Paster BJ, et al. (2008) Bacteremia associated with tooth brushing and dental extraction. Circulation 117: 3118-3125.

17. Complete vs Culprit-only Revascularization to Treat Multivessel Disease After Primary PCI for STEMI (COMPLETE).

18. Partridge RE, Duthie JJ (1963) Controlled Trial of the Effect of Complete Immobilization of the Joints in Rheumatoid Arthritis. Ann Rheum Dis 22: 91-99.

19. Tse D, Khan S, Clarke S (2009) Bacterial endocarditis complicating body art. Int J Cardiol 133: E28-E29.

20. Allison MC, Sandoe JA, Tighe R, Simpson IA, Hall RJ, et al. (2009) Antibiotic prophylaxis in gastrointestinal endoscopy. Gut 58: 869-880. 